\title{
Global Temperature Trends Adjusted for Unforced Variability
}

\author{
Craig Loehle \\ National Council for Air and Stream Improvement, Inc., United States
}

Copyright $(2015$ by authors, all rights reserved. Authors agree that this article remains permanently open access under the terms of the Creative Commons Attribution License 4.0 International License

\begin{abstract}
Multidecadal climate variability has proven difficult to deal with when estimating temperature trends. This possible unforced internal oscillation of the climate system provides an opportunity to correct temperature trends. The Atlantic Multidecadal Oscillation (AMO) is proposed as a potential index for this unforced variability. The AMO pattern does not appear to correspond to forcing histories used by the IPCC. Subtracting a scaled version of the AMO from the Hadley global temperature data produced damped decadal-scale fluctuations in the temperature data. The adjusted dataset is highly correlated with the anthropogenic forcing history from IPCC AR5. The linear post-1970 temperature trend is $0.83^{\circ} \mathrm{C} /$ century vs. $1.63^{\circ} \mathrm{C} /$ century for the raw data. Thus almost exactly half of the post- 1970 warming is possibly natural. The use of the AMO as an index of unforced variability is supported by the fact that subtracting it simplifies the temperature response by damping the peaks and troughs consistently.
\end{abstract}

Keywords $\mathrm{AMO}, \mathrm{CO}_{2}$ Rise, Natural Variability, Periodic Model, Radiative Forcing

\section{Introduction}

The potential existence of internal oscillations in the Earth climate system may complicate attempts to estimate temperature trends and climate sensitivity [1]. This is particularly true for multidecadal oscillations, which are not well-captured by General Circulation Models (GCMs) and are not causally understood, and therefore are not easy to subtract from secular trends. Various empirical methods for characterizing trends (e.g., $[2,3]$ ) do not resolve the problem of how to separate these oscillations from the forced climate components. Such oscillations can occur due to feedbacks in the climate system (e.g., persistent ocean warm pools, salinity changes) that tend to maintain systems of winds and currents [4,5]. Loehle and Scafetta[6] extensively documented the fact that these oscillations can in many cases be detected in records going back many hundreds of years and are thus not an artifact or chance occurrence.

Detecting the anthropogenic component of warming in the face of noise (in this case an internal oscillation) is possible if the noise can be characterized and subtracted. This can be done, for example, by using the Atlantic Multidecadal Oscillation (AMO) as a direct index of this variability. Physical mechanisms for the AMO have been proposed [4,5]. McCarthy et al.[7] proposed that ocean current variations could be linked to AMO behavior. The AMO has been shown to have strong linkages to patterns of precipitation at a great distance (e.g., [8]). While Booth et al.[9] claim that North Atlantic sea surface temperatures (SSTs) are strongly driven by aerosols, they explain mainly secular trends, whereas the AMO is detrended. While others have used the El Niño-Southern Oscillation (ENSO) as an index of internal oscillations (e.g., [10]), it is here hypothesized that the AMO is perhaps more consistently characterized and may be more reliable as a metric of internal oscillations. The validity of these suppositions can be evaluated based on the results presented.

\section{Methods}

The Hadley Center HadCRUT4 global temperature data (http://www.metoffice.gov.uk/hadobs/hadcrut4) were downloaded in January 2015. This dataset is a historical reconstruction of land and sea surface temperatures based on weather station and other data. The AMO monthly unsmoothed index (after [11]) was also downloaded in January 2015, including 1856 through 2014 (Fig. 1(a)). Due to greater uncertainty for older data, the analysis focused on post-1900 data. Yearly means were computed (Fig. 1(b)). Periodicity and trends of the AMO data were evaluated.

The AMO data were scaled vertically to minimize the variance in the (temperature - AMO) data. The result of subtracting the scaled AMO from the temperature data is designated the adjusted Hadley data. This represents a temperature series with internal (unforced) oscillations removed. Anthropogenic forcing data were obtained from IPCC AR5 WGI. These values, in $\mathrm{Wm}^{-2}$, are relative to a 0 
baseline in 1750 and thus represent additional forcing compared to pre-industrial levels. Total non- $\mathrm{CO}_{2}$ anthropogenic forcings were converted to $\mathrm{CO}_{2}$ equivalents based on AR5 Table AII.1.2. These equivalents were added to the $\mathrm{CO}_{2}$ levels on start and end dates to obtain $\mathrm{CO}_{2}$ equivalent forcings in order to calculate the percent of log $\mathrm{CO}_{2}$ doubling over the interval to 2010. This percent doubling was used to scale the warming over the length of the series (e.g., 1970 to 2010 for the AMO model) out to a full $\mathrm{CO}_{2}$ equivalent doubling. For example, a $0.5^{\circ} \mathrm{C}$ warming over a period having half a doubling (log scale) would give $1.0^{\circ} \mathrm{C}$ TCR (transient climate response) where TCR is the warming expected over short (multi-decadal) time periods. Note that this method of estimating TCR does not require any information about ocean heat content, which is a difficult parameter to estimate.
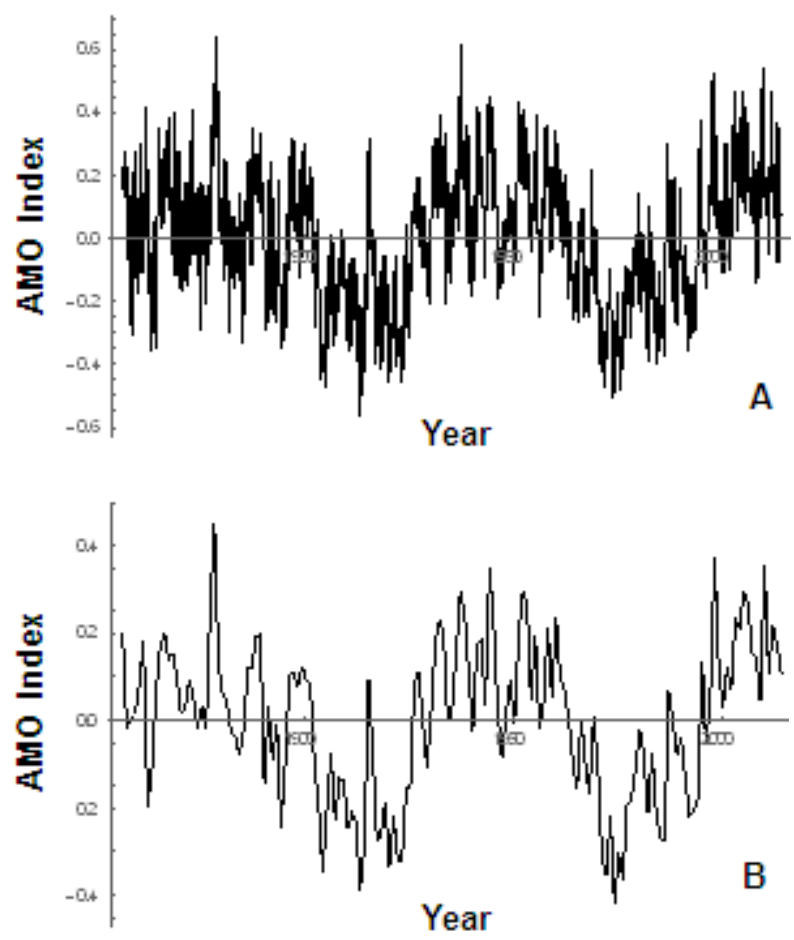

Figure 1. AMO Index from

www.esrl.noaa.gov/psd/data/correlation/amon.us.long.data for 1856-2014: A) monthly data. B) yearly means (note different scales); [11].

Equilibrium climate sensitivity (ECS) is the longer-term response of the Earth system to a change in forcing. The lag required to achieve equilibrium results from the very slow turnover of the ocean. While the ocean is warming, it acts as a heat sink. The time required for the full ocean to warm in response to enhanced radiative forcing is at least a few hundred years and might be much longer. If the latter, then ECS values are not particularly policy-relevant compared to the more immediate TCR value. ECS was calculated using heat uptake efficiency from Forster et al.[12] based on Top of Atmosphere (TOA) radiative balance data from Loeb et al.[13] to get $\mathrm{K}=0.59$ and an effective forcing value for $\mathrm{CO}_{2}$ doubling of $3.71 \mathrm{Wm}^{-2}[14]$. The scaling is then

$$
E C S=\frac{3.71}{\left(\frac{3.71}{\mathrm{TCR}}-0.59\right)}
$$

\section{Results}

The AMO index (Fig. 1(b)) was found to have a periodicity of 67.8 years. The linear trend was nearly flat with $95 \%$ confidence intervals that included zero, so no warming trend was evident in this index. The sum of all AMO values is zero.

The optimal scaling for the AMO index to convert it to comparable ${ }^{\circ} \mathrm{C}$ was 0.625 . The result of subtracting the AMO from the Hadley data (Fig. 2) shows the adjusted temperatures to have reduced variability, especially at the scale of decades. The new data standard deviation is $26 \%$ lower. Importantly, the adjusted Hadley data after about 1950 become approximately linear.

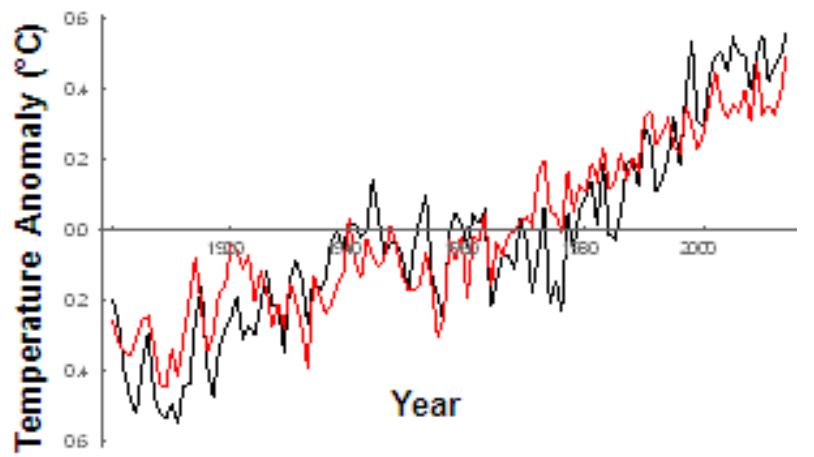

Figure 2. Hadley global temperature anomalies (black) with series adjusted by subtracting the scaled AMO (red).

The IPCC forcing data (Fig. 3) shows $\mathrm{CO}_{2}$ and total anthropogenic effective radiative forcing to be nearly identical up to a transition at about 1970 where both curves change slope but total anthropogenic more so.

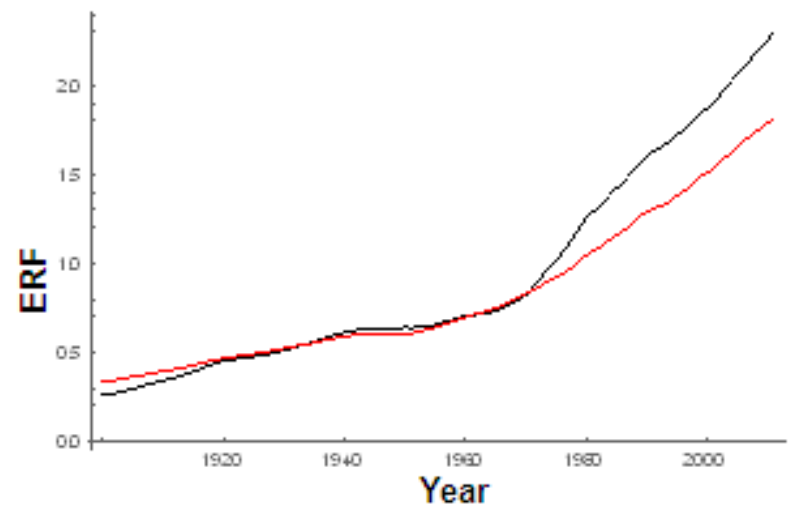

Figure 3. Effective radiative forcing $\left(\mathrm{Wm}^{-2}\right)$ from $\mathrm{IPCC}$ for $\mathrm{CO}_{2}$ (red) and total anthropogenic (black).

The total $\mathrm{CO}_{2}$ forcing and anthropogenic forcing were scaled for comparison and overlaid on the adjusted temperature data (Fig. 4). The forcing and adjusted temperature data both exhibit two fairly linear segments with the same break point at about 1970 . The anthropogenic 
correlation with temperature is $0.92 . \mathrm{CO}_{2}$ forcing alone appears similar and fits slightly better (correlation of 0.93 ) but is not used in further analyses since it is traditional to use total forcings for analyses. The adjusted temperature trend post-1970 (and really post-1950) is clearly approximately linear and no sophisticated methods are needed to evaluate the trend. The linear adjusted temperature trend from 1900 to 1969 is $0.41^{\circ} \mathrm{C} /$ century $(0.30-0.5295 \%$ c.i. $)$ and from 1970 to 2014 is $0.83^{\circ} \mathrm{C} /$ century $(0.71-0.9995 \%$ c.i. $)$. Converting total anthropogenic forcing to $\mathrm{CO}_{2}$ equivalents, the rise in $\mathrm{CO}_{2}$ equivalents from 1970 to 2010 is 0.282 of a log doubling from 1970 levels with a $0.341{ }^{\circ} \mathrm{C}$ temperature rise over this interval. This gives $\mathrm{TCR}=1.21$ and $\mathrm{ECS}=$ 1.5 .
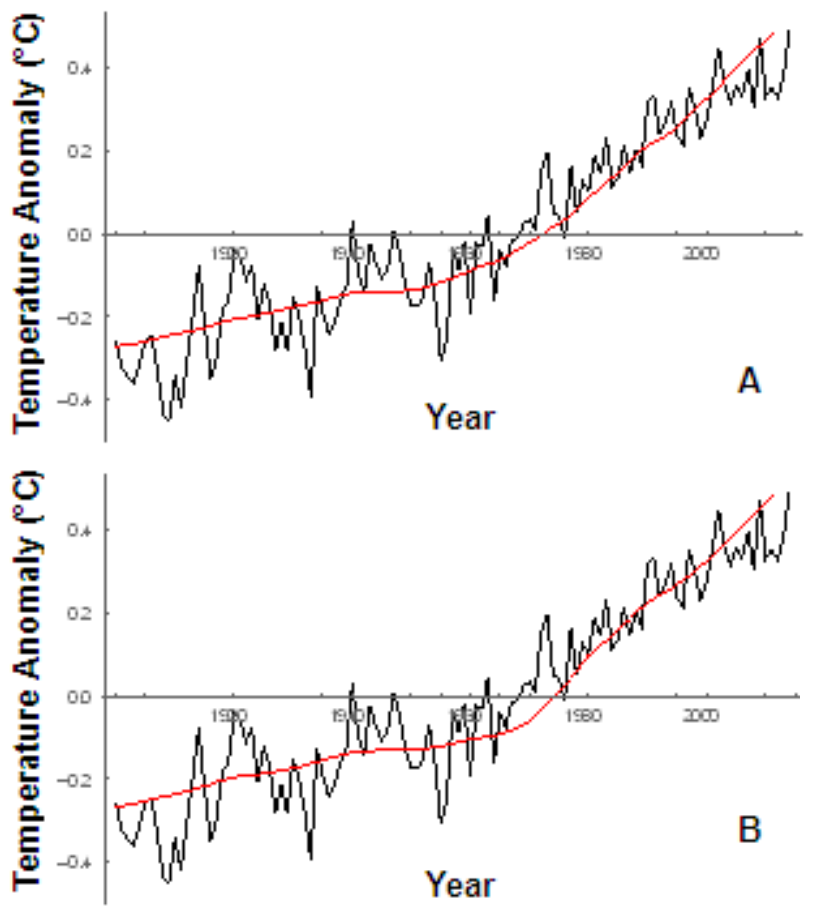

Figure 4. Adjusted Hadley global temperature (black) vs. A) scaled (arbitrary scale) $\mathrm{CO}_{2}$ forcing (red) and B) scaled (arbitrary scale) total anthropogenic forcing (red)

\section{Discussion}

The cycle evident in the AMO index (Fig. 1) is not present in the natural forcings time series used by IPCC AR5, is not well-captured by GCM simulations [15] and shows no linear trend by itself, and thus likely represents an internal climate oscillation, as argued by Chylek et al.[16] and Wyatt and Curry[5]. The AMO cycle of 67.8 years is consistent with periodic climate cycles found in numerous geophysical datasets (see [6]). There is some evidence for northern hemisphere climate periodicities of 60-70 years being linked to solar activity [17]. A mechanism has been proposed for linking hemispheric temperature oscillations, with the North Atlantic playing a key role [18]. Comparing this index to HadCRUT4 data, it is clear that the AMO captures many details of the temperature history and damps decadal temperature fluctuations when subtracted.

There is evidence, after subtracting the AMO, for a two-part linear trend in both the forcing and temperature histories, with a transition about 1970 (Fig. 4). This coincidence of shape, which is much less evident before subtracting the AMO and corresponds to a correlation of 0.923, suggests that the AMO does in fact capture some aspects of internal climate variability.

The linear temperature trend after 1970 of only $0.83^{\circ} \mathrm{C} /$ century is approximately half of the $1.63^{\circ} \mathrm{C} /$ century (1.43-1.86 95\% c.i.) trend after 1970 in the raw Hadley data. This value is much lower than those determined by trend analyses based on empirical models that do not attempt to subtract internal oscillations (e.g., [3]). The UAH (University of Alabama Huntsville) satellite lower troposphere temperature (version 6) trend over most of this period is $1.1{ }^{\circ} \mathrm{C} /$ century. The $0.83^{\circ} \mathrm{C} /$ century rate matches the claim from IPCC that half of the recent warming is due to human influences. If the GCMs are matching the rapid rise after 1970, of which half is due to natural internal oscillations, then they are actually overestimating warming.

On the other hand, if the pre-1970 linear trend of $0.41{ }^{\circ} \mathrm{C} /$ century is due to a natural longer-term cycle (per $[6,19]$ ), then only $0.83-0.41$ or $0.42^{\circ} \mathrm{C} /$ century would be due to anthropogenic causes, or $1 / 4$ of the unadjusted post- 1970 trend.

The analysis here makes almost no assumptions. All that is done is to scale the AMO and subtract it. Sensitivity is then simply calculated from the linear warming after 1970 and the corresponding $\mathrm{CO}_{2}$ equivalents of forcing. Solar and volcanic activities are treated as noise. No explicit model based on forcing is developed; rather, the forcing history is scaled and overlain to show the similarity of shape. The coincidence of breakpoints suggests that any temperature lags in response to forcing are at most a few years. The TCR and ECS results reported are much lower than the IPCC GCM model-based estimates and are consistent with previous data-based sensitivity estimates. Multiple studies ([20-22] and references therein) report equilibrium sensitivity near or less than $2^{\circ} \mathrm{C}$. For example, Lewis[23], using an objective Bayesian approach, obtained a mode and median ECS of $1.6^{\circ} \mathrm{C}$ compared to 1.5 obtained here. TCR estimates here should be considered more reliable than ECS estimates, which are based on some assumptions about ocean turnover. Ocean heat storage estimates are not clearly reliable $[24,25]$ and thus their use when estimating TCR introduces error of some unknown magnitude. Overall, the approach reported here minimizes errors due to poorly measured or poorly understood Earth system processes, as well as due to the effect of errors in the forcing history. It is also important to note that an extrapolation of this 1970 to 2014 linear trend into the future is much less than proposed by IPCC for the $21^{\text {st }}$ Century under any scenario and most models. No support for accelerating warming can be seen in these results after 1970 . 
The total uncertainty in this analysis is not fully quantifiable. Some of the year-to-year temperature data error is captured by the confidence intervals on trends. The differences between the various temperature datasets are not. There is no appreciable error in the $\mathrm{CO}_{2}$ data but the AR5 estimates of total anthropogenic forcing may have error. If this ratio is too high (low) then the TCR estimate would rise (fall). If Stevens's[26] argument for the aerosol forcing lower bound being less negative than assumed is correct, then the sensitivity lower bound used by IPCC would be lower. On the other hand, Olson et al.[1] argue that unresolved internal climate variability could lead to $0.84^{\circ} \mathrm{C}$ average discrepancy in climate sensitivity estimates, based on simulations. The use of the AMO here to capture internal variability could significantly reduce this uncertainty. Errors in the AMO data are not easily ascertained. Uncertainty in ocean turnover used to calculate ECS are also poorly known. True confidence intervals are likely unknowable at this time given uncertain forcing histories and difficulties in determining global temperature data and are thus not computed for TCR and ECS. Temperature trend confidence intervals computed here are probably underestimates.

Other similar analyses bear mentioning. Chylek et al.[16] independently developed a similar model based on the AMO and the anthropogenic forcing history fit to the Goddard Institute for Space Studies (GISS) dataset and obtained an excellent fit, though they did not estimate sensitivity. Spencer and Braswell[10] in a 1D simulation including ocean heat uptake showed that including ENSO in the model improved model-observation agreement and affected the feedback parameter value. However, they concluded that ocean heat change data do not adequately constrain estimates of sensitivity in their analysis, supporting the avoidance of such data in the present analysis. Cawley et al.[27] developed a model based on the HadCRUT4 data, RCP8.5 forcings, and an ENSO index, obtaining a best-estimate for TCR of $1.662\left(95 \%\right.$ HPD credible interval 1.31 to $2.02^{\circ} \mathrm{C}$ ). Note that if they used the substantially higher total forcings from the IPCC AR5 report, their TCR value would end up lower, perhaps close to results obtained here. Their claim of finding an error in Loehle's[22] model in fact resulted from using a different version of the Hadley data, emphasizing how the underlying data keeps changing. The fact that these models all give excellent fits to the data without the need for GCM mechanistic detail suggests that there is great potential in these simple approaches. On the other hand, their differences suggest some ambiguity which cannot be resolved by model goodness of fit, since they are all similar in this regard.

\section{Conclusions}

The pause in warming over the past $15+$ years has opened the question of natural variability in the climate system. If this natural variability can be characterized, then temperature trends might be more reliably determined. It is shown here that by subtracting the $\mathrm{AMO}$, temperature variability at the decadal scale is reduced and a close match achieved with the pattern of anthropogenic forcing data. It is not claimed here that the AMO is unique in capturing internal variability. Rather, this initial effort seeks to open this line of enquiry to reducing the uncertainty due to internal variability. Climate sensitivity estimated by this method is consistent with other data-based estimates, and much less than from model-based estimates.

\section{Acknowledgements}

No outside funding was obtained for this work. Thanks to Nicholas Lewis for advice and references and to William Happer for a helpful review.

\section{REFERENCES}

[1] R. Olson, R. Sriver, W. Chang, M. Haran, N. M. Urban, K. Keller. What is the effect of unresolved internal climate variability on climate sensitivity estimates? Journal of Geophysical Research: Atmospheres, Vol.118, No.10, 4348-4358, 2013.

[2] Z. Wu, N. E. Huang, S. R. Long, C.-K. Peng. On the trend, detrending, and variability of nonlinear and nonstationary time series, Proceedings of the National Academy of Sciences, Vol.104, 14889-14894, 2007.

[3] B. B. B. Booth, N. J. Dunstone, P. R. Halloran, T. Andrews, N. Blllouin. Aerosols implicated as a prime driver of twentieth-century North Atlantic climate variability, Nature, Vol.484, 228-232, 2012.

[4] M. Dima, D. Lohmann. A hemispheric mechanism for the Atlantic multidecadal oscillation, Journal of Climate, Vol.20, No.11, 2706-2719, 2007.

[5] M. G. Wyatt, J. A. Curry. Role for Eurasian Arctic shelf ice in a secularly varying hemispheric climate signal during the $20^{\text {th }}$ century, Climate Dynamics, Vol.42, No.9-10, 2763-2782, 2014.

[6] C. Loehle, N. Scafetta. Climate change attribution using empirical decomposition of historical time series, Open Atmospheric Science Journal, Vol.5, 74-86, 2011.

[7] G. D. McCarthy, I. D. Haigh, J. J.-M. Hirschi, J. P. Grist, D. A. Smeed. Ocean impact on decadal Atlantic climate variability revealed by sea-level observations, Nature, Vol.521, No.7553, 508-510, 2015.

[8] S. Nigam, B. Guan, A. Ruiz-Barradas. Key role of the Atlantic Multidecadal Oscillation in $20^{\text {th }}$ century drought and wet periods over the Great Plains, Geophysical Research Letters, Vol.38, L16713, 2011.

[9] Z. Wu, N. E. Huang, J. M. Wallace, B. V. Smoliak, X. Chen. On the time-varying trend in global-mean surface temperature, Climate Dynamics, Vol.37, 759-773, 2011. 
[10] R. W. Spencer, W. D. Braswell. The role of ENSO in global ocean temperature changes during 1955-2011 simulated with a 1D climate model, Asia-Pacific Journal of Atmospheric Sciences, Vol.50, No.2, 229-237, 2014.

[11] D. B. Enfield, A. M. Mestas-Nunez, P. J. Trimble. The Atlantic multidecadal oscillation and its relationship to rainfall and river flows in the continental US, Geophysical Research Letters, Vol.28, No.10, 2077-2080, 2001.

[12] P. M. Forster, T. Andrews, P. Good, J. M. Gregory, L. S. Jackson, M. Zelinka. Evaluating adjusted forcing and model spread for historical and future scenarios in the CMIP5 generation of climate models, Journal of Geophysical Research: Atmospheres, Vol.118, No.3, 1139-1150, 2013.

[13] N. G. Loeb, J. M. Lyman, G. C. Johnson, R. P. Allan, D. R. Doelling, T. Wong, B. J. Soden, G. L. Stephens. Observed changes in top-of-the-atmosphere radiation and upper-ocean heating consistent within uncertainty, Nature Geoscience, Vol.2, No.2, 110-113, 2012.

[14] G. Myhre, E. J. Highwood, K. P. Shine, F. Stordal. New estimates of radiative forcing due to well mixed greenhouse gases, Geophysical Research Letters, Vol.25, No.14, 2715-2718, 1998

[15] S. Kravtsov, M. G. Wyatt, J. A. Curry, A. Tsonis. Two contrasting views of multidecadal climate variability in the twentieth century, Geophysical Research Letters, Vol.41, No.19, 6881-6888, 2014.

[16] P. Chylek, J. D. Klett, G. Lesins, M. K. Dubey, N. Hengartner. The Atlantic multidecadal oscillation as a dominant factor of oceanic influence on climate, Geophysical Research Letters, Vol.41, No.5, 1689-1697, 2014.

[17] M. Ogurtsov, M. Lindholm, R. Jalkanen, S. Veretenenko. Evidence for the Gleissberg solar cycle at the high-latitudes of the Northern Hemisphere, Advances in Space Research, Vol.55, No.5, 1285-1290, 2015.
[18] Z. Wang, X. Zhang, Z. Guan, B. Sun, X. Yang, C. Liu. An atmospheric origin of the multi-decadal bipolar seesaw, Scientific Reports, Vol.5, 8909, 2015.

[19] C. Loehle, S. F. Singer. Holocene temperature records show millennial-scale periodicity, Canadian Journal of Earth Sciences, Vol.47, No.10, 1327-1336, 2010

[20] M. Aldrin, M. Holden, P. Guttorp, R. B. Skeie, G. Myhre, T. K. Berntsen. Bayesian estimation of climate sensitivity based on a simple climate model fitted to observations of hemispheric temperature and global ocean heat content, Environmetrics, Vol.23, No.3, 253-271, 2012.

[21] J. D. Annan, J. C. Hargreaves. On the generation and interpretation of probabilistic estimates of climate sensitivity, Climatic Change, Vol.104, No.3-4, 423-436, 2011.

[22] C. Loehle. A minimal model for estimating climate sensitivity, Ecological Modelling, Vol.276, 80-84, 2014.

[23] N.H. Lewis 2015. An objective Bayesian improved approach for applying optimal fingerprint techniques to estimate climate sensitivity. J. Climate 26:7414-7429.

[24] R. E. Hadfield, N. C. Wells, S. A. Josey, J. J.-M. Hirschi. On the accuracy of North Atlantic temperature and heat storage fields from Argo, Journal of Geophysical Research, Vol.112, No.C1, C01009, 2007.

[25] H. B. Dieng, A. Cazenave, K. von Schuckmann, M. Ablain, B. Meyssignac. Sea level budget over 2005-2013: missing contributions and data errors, Ocean Science Discussions, Vol.12, No.3, 701-734, 2015.

[26] B. Stevens. Rethinking the lower bound on aerosol radiative forcing, Journal of Climate, Vol.28, No.12, 4794-4819, 2015.

[27] G. C. Cawley, K. Cowtan, R. G. Way, P. Jacobs, A. Jokimäki. On a minimal model for estimating climate sensitivity, Ecological Modelling, Vol.297, 20-25, 2015. 